
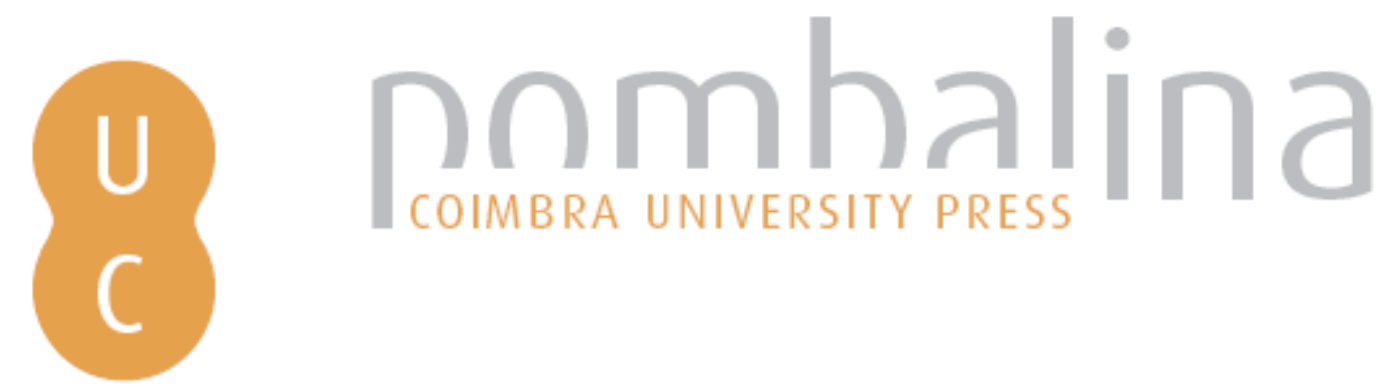

\title{
Estudo preliminar de fitomineração utilizando alyssumserpyllifoliumdesf. subsp. lusitanicum (Dudley\& P. Silva) em solos serpentiníticos dos maciços de Bragança e de Morais (nordeste de Portugal)
}

\author{
Autor(es): $\quad$ Morais, I.; Campos, J. S.; Pratas, J.; Pita, F.
}

Publicado por: Imprensa da Universidade de Coimbra

URL persistente:

URI:http://hdl.handle.net/10316.2/31473

DOI:

DOI:http://dx.doi.org/10.14195/978-989-26-0531-9_34

Accessed : $\quad$ 26-Apr-2023 14:51:07

A navegação consulta e descarregamento dos títulos inseridos nas Bibliotecas Digitais UC Digitalis, UC Pombalina e UC Impactum, pressupõem a aceitação plena e sem reservas dos Termos e Condições de Uso destas Bibliotecas Digitais, disponíveis em https://digitalis.uc.pt/pt-pt/termos.

Conforme exposto nos referidos Termos e Condições de Uso, o descarregamento de títulos de acesso restrito requer uma licença válida de autorização devendo o utilizador aceder ao(s) documento(s) a partir de um endereço de IP da instituição detentora da supramencionada licença.

Ao utilizador é apenas permitido o descarregamento para uso pessoal, pelo que o emprego do(s) título(s) descarregado(s) para outro fim, designadamente comercial, carece de autorização do respetivo autor ou editor da obra.

Na medida em que todas as obras da UC Digitalis se encontram protegidas pelo Código do Direito de Autor e Direitos Conexos e demais legislação aplicável, toda a cópia, parcial ou total, deste documento, nos casos em que é legalmente admitida, deverá conter ou fazer-se acompanhar por este aviso.

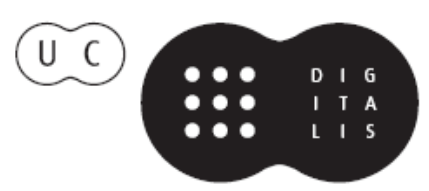





\title{
ESTUDO PRELIMINAR DE FITOMINERAÇÁO UTILIZANDO ALYSSUM SERPYLLIFOLIUM DESF. SUBSP. LUSITANICUM (DUDLEY \& P. SILVA) EM SOLOS SERPENTINÍTICOS DOS MACIÇOS DE BRAGANÇA E DE MORAIS (NORDESTE DE PORTUGAL)
}

\author{
PRELIMINARY STUDIE OF PHYTOMINING USING ALYSSUM \\ SERPYLLIFOLIUM DESF. SUBSP. LUSITANICUM (DUDLEY \\ \& P. SILVA) IN SERPENTINIC SOILS OF BRAGANÇA \\ AND MORAIS MASSIFS (NORTHEAST OF PORTUGAL)
}

\begin{abstract}
Resumo - O presente trabalho é um estudo preliminar onde se testa a possibilidade de utilização do Alyssum serpyllifolium susbp. lusitanicum como um biominério na fitomineração de solos serpentiníticos. Esta espécie, endémica dos solos ultrabásicos dos maciços de Bragança e de Morais, é uma hiperacumuladora de $\mathrm{Ni}$, podendo conter mais de $6500 \mathrm{mg} / \mathrm{kg}$ (Peso Seco) deste elemento. Pretende-se verificar qual a variabilidade dos teores de Ni contidos na planta em diferentes locais, se é dependente do Ni contido no solo ou na fracção biodisponível. Elaborar uma pré avaliação da biomassa produzida em condiçôes naturais e da quantidade de níquel que se pode retirar por unidade de área. Os resultados obtidos revelam que a sua produção de biomassa média, considerando apenas as partes aéreas, é de cerca de 7,2 t/ha, com um teor médio $0,41 \% \mathrm{Ni}(0,38 \%$ de $\mathrm{Ni}$ teor ponderado), permitindo retirar cerca de $27,5 \mathrm{~kg} / \mathrm{ha}$ por colheita, em condiçôes naturais. Considerando a depleção de $\mathrm{Ni}$ do solo por sucessivas colheitas verifica-se também que os solos serpentiníticos podem ser uma fonte importante para a aplicação da fitomineração utilizando esta espécie.
\end{abstract}

Palavras-chave - fitomineração, níquel, Alyssum, solos serpentiníticos, Bragança

Abstract - This paper is a preliminary study where is tested the possibility of using Alyssum serpyllifolium susbp. lusitanicum as a bio-ore in phytomining, using serpentinic

\footnotetext{
${ }^{1}$ Centro de Geociências, Departamento de Ciências da Terra da FCTUC; jpratas@dct.pt; fpita@dct.pt

${ }^{2}$ Departamento de Ciências da Terra da FCTUC; igorbatista3@hotmail.com; joana_scampos@hotmail.com
} 
soils. This species, endemic to the serpentinic soils of Bragança and Morais massifs, is a Ni hyperaccumulator, and may contain more than $6500 \mathrm{mg} / \mathrm{kg}(\mathrm{DW})$ of this element. In this study we intend to verify that the variability of the levels of $N i$ contained in the plant in different locations, if it is dependent on the Ni contained in the soil or in the bioavailable soil fraction. It also allows develop a pre evaluation of the biomass produced under natural conditions and the amount of nickel that can remove per unit area. The results show that the average production of biomass, considering only the aerial parts is about $7.2 \mathrm{t} / \mathrm{ha}$, with an average grade of $0.41 \% \mathrm{Ni}$, allowing withdraw around $27.5 \mathrm{~kg} / \mathrm{ha}$ per crop, under natural conditions. Considering the depletion of $N i$ from the soil through successive crops is also found that the serpentine soils may be an important source for the application of phytomining using this plant species.

Keywords-phytomining, nickel, Alyssum, serpentinic soils, Bragança

\section{1 - Introduçáo}

Os solos serpentiníticos, apesar de pouco abundantes, estão dispersos por várias áreas do globo, ocorrendo sobre serpentinitos ou outras rochas ultrabásicas: NW da América, E do Canadá, País de Gales e Escócia, NE de Cuba, Portugal, Itália, Península dos Balcãs, Turquia, Brasil Central, Nova Caledónia, SE da Ásia, Filipinas, Japão, Zimbabué, Nova Zelândia, Moçambique, Timor e cintura de rochas verdes no W da Austrália que representam cerca de $13 \%$ do substrato geológico global (Menezes de Sequeira e Pinto da Silva, 1991).

Os ecossistemas dos solos serpentiníticos apresentam distintas comunidades de plantas endémicas (PINTO DA SILVA, 1968; BROOKS, 1987; ARIANOUTSOU et al., 1993; BAKER et al., 1993; ROSS, 1994; REEVES et al., 1996; FREITAS et al., 2004). Estes solos contêm teores desproporcionalmente elevados em Ni, Cr, Co, bem como uma baixa relação Ca/Mg (KRUCKEBERG, 1984; BROOKS, 1987; ADRIANO, 2001). Por esses motivos desenvolve-se sobre eles uma flora característica, tolerante ao excesso de $\mathrm{Ni}$ e $\mathrm{Cr}$ e que permite suportar o "stress" imposto pelas suas condições geoquímicas específicas. Nestas comunidades serpentiníticas têm-se encontrado espécies hiperacumuladoras de $\mathrm{Ni}$, contendo quantidades muito apreciáveis deste metal nos seus tecidos, com valores superiores a $5000 \mathrm{mg} / \mathrm{kg} \mathrm{em}$ material seco.

Em Portugal já há algum tempo que se conhece a presença do Alyssum serpyllifolium subsp. lusitanicum como sendo uma hiperacumuladora de Ni (MENEZES DE SEQUEIRA, 1968), contudo, poucos estudos têm sido feito sobre a sua fisiologia. BROOKS et al. (1981) fizeram testes de germinação em algumas espécies de Alyssum e verificaram que o A. serpyllifolium germinava bem em solos com concentraçôes de $\mathrm{Ni}$ superiores a $12000 \mathrm{mg} / \mathrm{kg}$.

Esta espécie encontra-se distribuída nos solos serpentiníticos portugueses dos maciços de Morais e Bragança e desenvolve-se sobre serpentinitos e outras rochas ultrabásicas como harzburgitos e dunitos.

Este trabalho tem por objetivos verificar se há variabilidade da distribuição da concentração de Ni no Alyssum serpyllifolium subsp. lusitanicum em diferentes locais dos 
referidos maciços, se existe uma relação entre a concentração de metal no solo (total ou biodisponível) com a concentração na planta e constituir um estudo preliminar sobre a sua possível utilização em fitomineração como formadora de um biominério de níquel. Esta possibilidade poderia permitir a obtenção de algum rendimento de solos de fraca aptidão agrícola e em áreas remotas.

\section{2 - Área de Estudo}

As duas áreas onde incidiu o estudo situam-se no Norte de Portugal, no distrito de Bragança. O maciço de Bragança e Vinhais (A) situa-se mais a norte da área em estudo e localiza-se nos concelhos de Bragança e Vinhais e o maciço de Morais (B) situa-se mais a sul no concelho de Macedo de Cavaleiros (Fig.1).

Geologicamente no maciço de Bragança-Vinhais individualizam-se duas sinformas: a de Vinhais-Vila Boa de Ousilhão-Samil e a de Mofreita-Espinhosela-Braçal, alongadas na direção NW-SE e separadas por uma antiforma (anticlinal de Ladeiro), onde aflora o Alóctone Inferior com xistos verdes, com intercalaçóes de filitos, serpentinitos, flaser gabros, anfibolitos de baixo grau e mármores. O maciço é deslocado por duas grandes falhas a de Bragança-Vilariça, NNE-SSW e a falha de Vinhais-Bragança E-W (Fig.2).

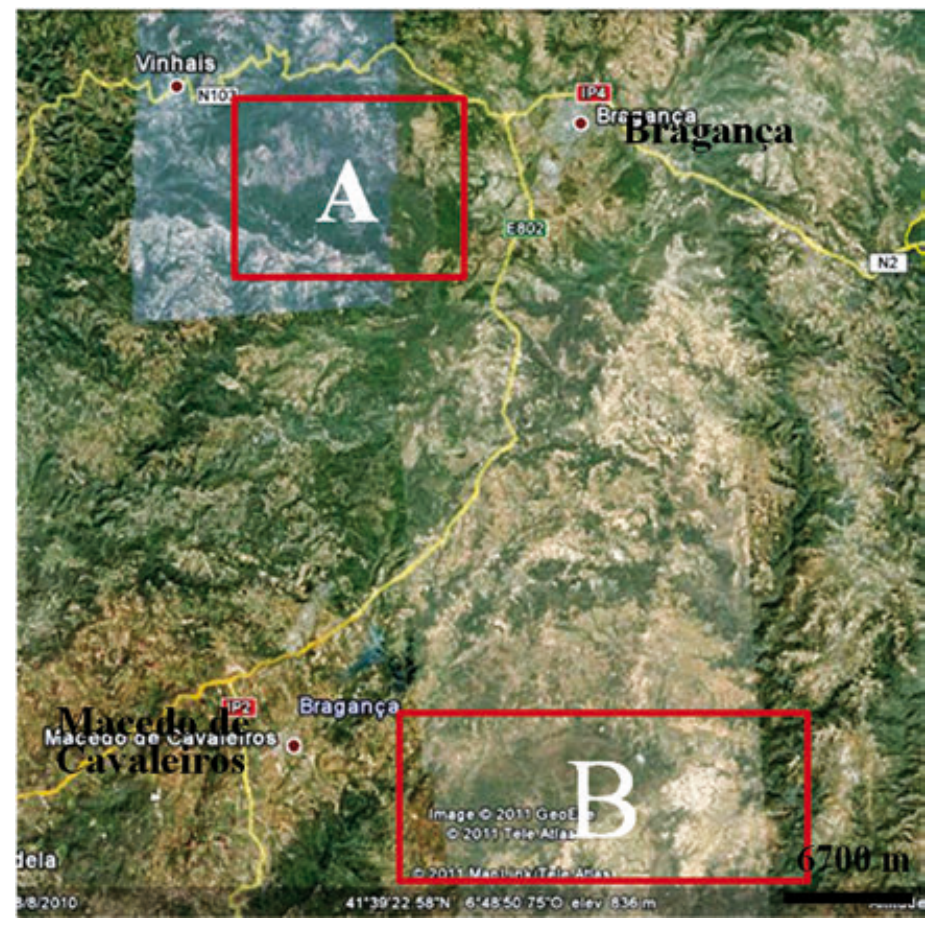

Fig. 1 - Imagem de Google Earth com a localização das áreas em estudo. A- Maciço de Bragança-Vinhais, B- Maciço de Morais (GOOGLE EARTH, 2011). 


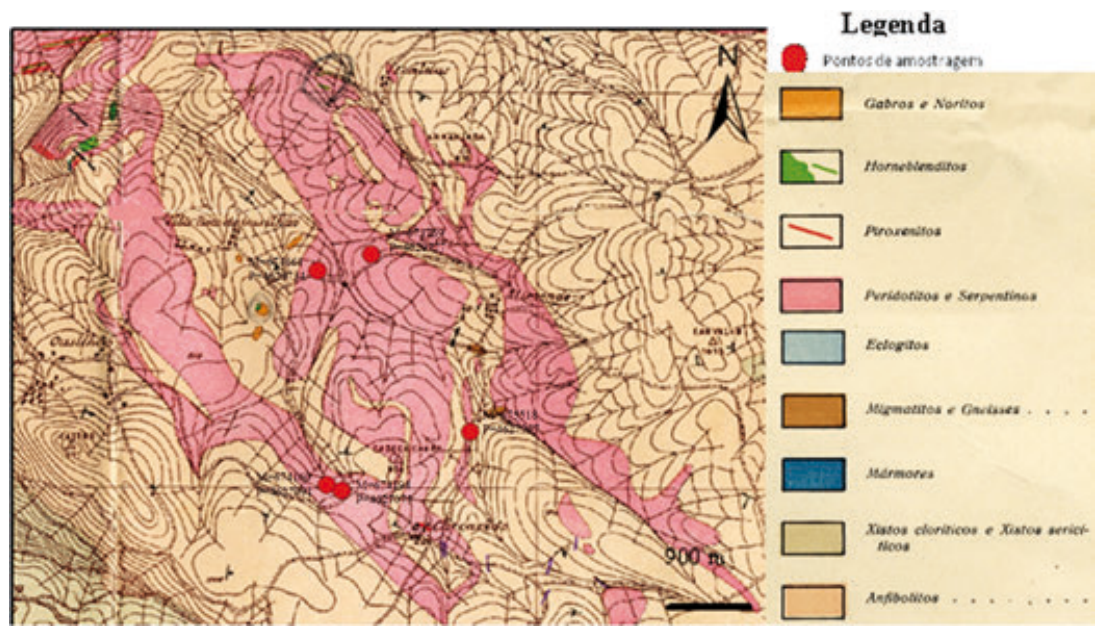

Fig. 2 - Excerto da carta geológica Bragança-Vinhais, 1:50000 (NEIVA, 1948), com a localização dos pontos de amostragem (Coordenadas UTM, WGS84).

O Maciço de Morais tem forma arredondada e é cortado na direção ENE-WSW pela falha de Morais, que é uma falha inversa, mergulhante para $\mathrm{N}$ e onde o bloco norte subiu em relação ao bloco sul. O Alóctone Superior é constituído por rochas granulíticas básicas e ultrabásicas, que constituem as unidades de Vinhas e Caminho Velho, ortognaisses ocelados, que se designam por ortognaisse da Lagoa, e por micaxistos, que se designam micaxistos da Lagoa. O complexo Ofiolítico é composto da base ao topo por: peridotitos serpentinizados, gabros melanocráticos, flaser gabros, complexo de dique em dique, anfibolitos e anfibolitos retromorfizados para xistos verdes. No monte de Morais, as rochas ultramáficas suportam cumes elevados e planos do maciço. Em termos petrográficos o maciço ultramáfico é essencialmente constituído por harzburguitos e dunitos (Fig.3).
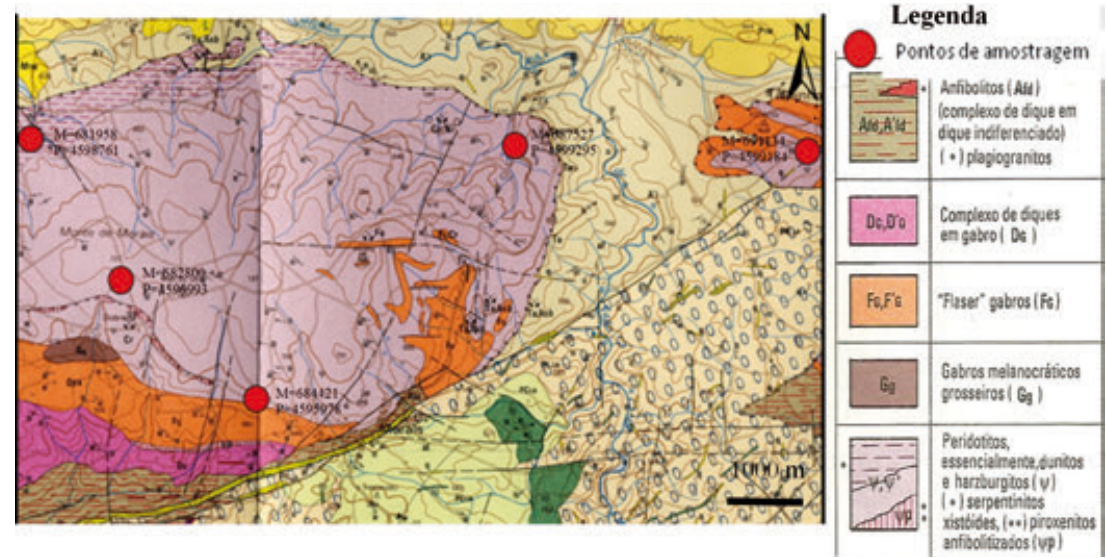

Fig. 3 - Excerto da carta geológica 7-D Macedo de Cavaleiros, 1:50000 (PEREIRA et al., 1998), com a localização dos pontos de amostragem (Coordenadas UTM, WGS84). 


\section{3 - Materiais e Métodos}

A amostragem das duas áreas foi feita de modo aleatório, tendo sido amostrados 10 locais, 5 em cada um dos maciços. A campanha de amostragens foi feita em junho de 2011 e foram recolhidas todas as plantas de A. serpyllifolium contidas numa área de cerca de $1 \mathrm{~m}^{2}$. Essa colheita incidiu sobra a totalidade da planta, incluindo raiz, sendo posteriormente separadas e tratadas individualmente. Foram depois secas e pesadas para se poder ter um cálculo inicial da biomassa. Nesta mesma área foi feita uma amostragem do solo representativa da mesma área de colheita das plantas.

Cada amostra de solo foi crivada a 80 mesh, homegeneizada e quarteada. As amostras de solos foram digeridas por dois processos: a) em água régia com auxílio de micro-ondas (Microwave 3000 - Anton Par); b) em acetato de amónio para se obter a concentração biodisponível e também com o auxílio do micro-ondas. Em ambos os casos as concentraçóes de $\mathrm{Co}, \mathrm{Cr}, \mathrm{Cu}, \mathrm{Ni}$ e $\mathrm{Zn}$ foram determinadas por espectrofotometria de absorção atómica (Thermo Solar M2).

As raízes e partes aéreas das plantas foram moídas separadamente e quarteadas para se retirarem amostras representativas. As análises efetuadas seguiram o método da via húmida, as plantas foram digeridas em ácido nítrico 65\% e peróxido de hidrogénio a $30 \%$, com auxílio do micro-ondas, sendo posteriormente determinados os mesmos elementos que para os solos, também por espectrofotometria de absorção atómica. Em todas elas foram efetuadas três réplicas e os valores obtidos considerados como a sua média.

\section{4 - Resultados e Discussão}

$\mathrm{Na}$ Tabela 1 apresentam-se os resultados obtidos para os solos das áreas de estudo. Pela sua análise verifica-se que estes solos apresentam, como é característica dos solos serpentiníticos, níveis elevados de $\mathrm{Co}, \mathrm{Cr}$ e $\mathrm{Ni}$, embora bastante variáveis em termos espaciais. Nesta primeira abordagem, e apesar de ainda não se dispor de uma grande quantidade de dados, verifica-se que os solos do maciço de Morais apresentam uma maior quantidade de $\mathrm{Cr}$ relativamente ao maciço de Bragança, enquanto que para os restantes elementos se observa o inverso. Relativamente à biodisponibilidade verifica-se que é maior nos solos do maciço de Morais para $\mathrm{Co}$, $\mathrm{Cr}$ e $\mathrm{Zn}$, enquanto que o $\mathrm{Cu}$ e $\mathrm{Ni}$ se encontram mais biodisponíveis no maciço de Bragança. 
Tabela 1 - Resultados analíticos dos solos da área de estudo (resultados expressos em mg/kg; para as plantas expressos em peso seco).

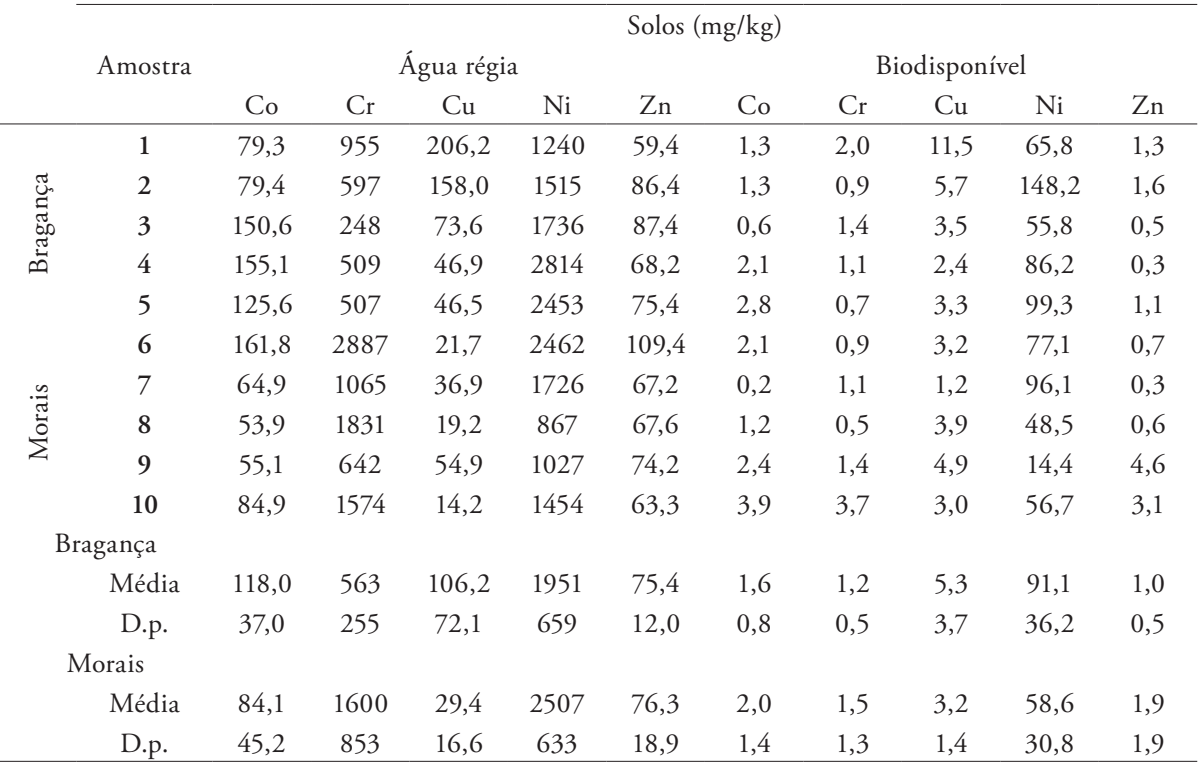

Com base nestes dados e efetuando uma análise de correlação múltipla, verifica-se que apenas existe correlação significativa entre as concentrações de Co e Ni total no solo e entre o $\mathrm{Cu}$ total e o biodisponível, o que leva a concluir da existência de uma grande discrepância entre o comportamento destes solos, que pode ser devido tanto ao seu grau evolutivo como à diferença litológica da rocha mãe ou mineralogia dos componentes do solo que contêm estes elementos.

Relativamente ao material vegetal; à exceção do $\mathrm{Cr}$, as partes aéreas Alyssum serpyllifolium subsp. lusitanicum concentram muito maior quantidade dos elementos analisados que as suas raízes (Tabela 2). Este comportamento poderá estar relacionado com a fraca mobilidade do $\mathrm{Cr}$, relativamente aos restantes elementos. Também se verifica que de um modo global a concentração destes elementos na planta é superior no maciço de Morais.

Comparativamente a valores observados em outras plantas metalotolerantes (PRATAS, 1996; FAVAS et al., 2003; FREITAS et al., 2004; PRASAD et al., 2006), verifica-se que as concentraçôes de $\mathrm{Zn}$ e $\mathrm{Cu}$ estão dentro dos valores normais do fundo biogeoquímico, enquanto que para Co e $\mathrm{Cr}$ mostram acumulaçóes relativamente elevadas, tal como seria de esperar, em face dos elevados teores encontrados no solo. Relativamente ao $\mathrm{Ni}$, há uma grande capacidade de hiperacumulação contudo bastante variável espacialmente.

Para verificar se existia alguma relação entre as concentraçôes encontradas no solo e na planta fez-se uma análise de correlação múltipla cujos resultados apenas indicaram a existência de correlaçáo significativa entre o $\mathrm{Cr}$ total no solo e na planta e entre o $\mathrm{Cu}$ biodisponível e na planta. Também se observou uma correlação significativa entre a concentração de $\mathrm{Cr}$ e Ni nas raízes e nas partes aéreas.

Ao contrário do sugerido na literatura (BROOKS, 1983) não se observa uma relação direta entre o teor de Ni no solo ou na fração biodisponível e a concentração de Ni na planta ou na sua raiz, sugerindo que outros fatores interferem no potencial 
de hiperacumulação desta espécie, como podem ser a relação $\mathrm{Ca} / \mathrm{Mg}$ no solo, a disponibilidade de nutrientes, o "stress" hídrico ou a competição entre oligoelementos.

Tabela 2 - Resultados analíticos observados no Alyssum serpyllifolium subsp. lusitanicum. (valores expressos $\mathrm{em} \mathrm{mg} / \mathrm{kg}$ com base em material seco).

\begin{tabular}{|c|c|c|c|c|c|c|c|c|c|c|}
\hline & \multicolumn{10}{|c|}{ Matéria vegetal (mg/kg DW) } \\
\hline \multirow[t]{2}{*}{ Amostra } & \multicolumn{5}{|c|}{ Partes aéreas } & \multicolumn{5}{|c|}{ Raiz } \\
\hline & Co & $\mathrm{Cr}$ & $\mathrm{Cu}$ & $\mathrm{Ni}$ & $\mathrm{Zn}$ & Co & $\mathrm{Cr}$ & $\mathrm{Cu}$ & $\mathrm{Ni}$ & $\mathrm{Zn}$ \\
\hline 1 & 10,3 & 7,4 & 7,4 & 6248 & 25,8 & 2,5 & 5,4 & 3,1 & 1419 & 19,0 \\
\hline 2 & 3,1 & 3,5 & 2,7 & 1945 & 17,0 & 1,1 & 4,1 & 2,7 & 645 & 14,2 \\
\hline 3 & 12,5 & 2,9 & 5,1 & 1541 & 14,4 & 9,0 & 6,6 & 3,2 & 518 & 12,5 \\
\hline 4 & 3,7 & 5,9 & 2,1 & 3965 & 11,9 & 8,4 & 21,9 & 3,1 & 1214 & 12,4 \\
\hline 5 & 5,9 & 3,8 & 2,3 & 3713 & 13,5 & 1,5 & 1,6 & 1,5 & 604 & 6,9 \\
\hline 6 & 7,8 & 17,1 & 4,8 & 4284 & 39,5 & 6,4 & 29,0 & 1,8 & 1414 & 25,3 \\
\hline \multirow{4}{*}{$\begin{array}{c}7 \\
8 \\
9 \\
10\end{array}$} & 9,1 & 6,9 & 2,3 & 4372 & 30,1 & 6,9 & 47,1 & 3,9 & 2177 & 27,8 \\
\hline & 12,2 & 3,8 & 4,4 & 3190 & 47,1 & 1,3 & 13,5 & 1,7 & 1129 & 23,6 \\
\hline & 9,9 & 6,0 & 5,8 & 4560 & 27,7 & 6,2 & 17,6 & 5,5 & 1404 & 36,8 \\
\hline & 9,7 & 19,4 & 4,5 & 6633 & 44,3 & 12,2 & 108,7 & 4,5 & 2620 & 31,0 \\
\hline \multicolumn{11}{|l|}{ Bragança } \\
\hline Média & 7,1 & 4,7 & 3,9 & 3482 & 16,5 & 4,5 & 7,9 & 2,7 & 880 & 13,0 \\
\hline D.p. & 4,1 & 1,9 & 2,3 & 1875 & 5,5 & 3,8 & 8,1 & 0,7 & 407 & 4,3 \\
\hline \multicolumn{11}{|l|}{ Morais } \\
\hline Média & 9,7 & 10,6 & 4,4 & 4608 & 37,8 & 6,6 & 43,2 & 3,5 & 1749 & 28,9 \\
\hline D.p. & 1,6 & 7,1 & 1,3 & 1252 & 8,6 & 3,9 & 38,9 & 1,7 & 624 & 5,2 \\
\hline
\end{tabular}

Com base nos valores obtidos de biomassa nos diferentes locais de amostragem para o Alyssum serpyllifolium subsp. lusitanicum e nas respectivas concentraçóes de $\mathrm{Ni}$ do mesmo material calculou-se a quantidade de $\mathrm{Ni}$ em metal contido nas partes aéreas das plantas por hectare (Tabela 3). Em condiçôes naturais é possível obter entre 4,08t e 9,37t de biomassa por hectare, com teores de $\mathrm{Ni}$ que variam de 0,15 a 0,66 \%. Verifica-se que a biomassa é mais elevada nos locais amostrados sobre o maciço de Bragança do que sobre o maciço de Morais e inversamente para o teor em níquel. Contudo, esta relação não reflete uma proporcionalidade inversa significativa quando se analisam a totalidade dos locais de amostragem.

Os resultados obtidos também permitem verificar que a produção de $\mathrm{Ni}$ em $\mathrm{kg}$ por hectare pode variar entre os 12,2 e os 44,0 com uma média de $27,5 \mathrm{~kg} / \mathrm{ha}$. Atendendo à cotação atual do níquel (13850 €/t em janeiro de 2012) verifica-se que o valor obtido por hectare e por cada colheita pode varia de cerca de $170 €$ a $610 €$, com uma média de $380 €$. Também se verifica que, apesar da variação de biomassa e teor observada nas amostras das plantas retiradas dos dois maciços, a produção final de metal é similar.

Para verificar a depleção do níquel no solo de modo a termos uma aproximação de uma possível viabilidade dum processo de fitomineração sobre estes solos, elaboraram-se os cálculos cujos resultados se apresentam na Tabela 3, tendo por base que o solo terá uma espessura média de $50 \mathrm{~cm}$ e ausência de processos pedogénicos que levem à formação de novo solo e à biodisponibilização de Ni.

Com base nos valores aqui obtidos verifica-se que esse solo poderá suportar 5 a 60 culturas, com uma média de 23 culturas, considerando apenas o Ni biodisponível. 
Considerando o Ni total presente no solo esse número de culturas variará entre as 211 e as 1067. Estes valores permitem esperar que não haverá problemas de esgotamento do Ni no solo, tanto mais que se está a considerar uma situação extrema, na prática não expectável.

Tabela 3 - Valores da biomassa, níquel bioacumulado e seu valor económico e número de culturas suportadas pelo solo.

\begin{tabular}{|c|c|c|c|c|c|c|c|c|}
\hline \multirow[t]{2}{*}{ Amostra } & \multirow{2}{*}{$\begin{array}{c}\text { Biomassa } \\
(\mathrm{kg} / \mathrm{ha})\end{array}$} & \multirow{2}{*}{$\begin{array}{c}\text { Teor } \\
(\mathrm{mg} / \mathrm{kg})\end{array}$} & \multirow{2}{*}{$\begin{array}{c}\text { Ni metal } \\
(\mathrm{kg} / \mathrm{ha})\end{array}$} & \multirow{2}{*}{$\begin{array}{l}\text { Valor } \\
(€ / \text { ha })\end{array}$} & \multicolumn{2}{|c|}{ Ni biodisponível } & \multicolumn{2}{|c|}{$\mathrm{Ni}$ total } \\
\hline & & & & & $\mathrm{kg} / \mathrm{ha}$ & $\mathrm{n}^{\circ}$ culturas & $\mathrm{kg} / \mathrm{ha}$ & $\mathrm{n}^{\circ}$ culturas \\
\hline 1 & 7040 & 6248 & 44,0 & 609 & 493 & 11 & 9299 & 211 \\
\hline 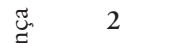 & 9370 & 1945 & 18,2 & 252 & 1112 & 61 & 11359 & 623 \\
\hline స్ల & 7920 & 1541 & 12,2 & 169 & 419 & 34 & 13017 & 1067 \\
\hline صี & 8300 & 3965 & 32,9 & 456 & 647 & 20 & 21103 & 641 \\
\hline 5 & 7950 & 3713 & 29,5 & 409 & 745 & 25 & 18396 & 623 \\
\hline 6 & 8890 & 4284 & 38,1 & 527 & 578 & 15 & 18463 & 485 \\
\hline 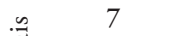 & 5830 & 4372 & 25,5 & 353 & 721 & 28 & 12941 & 508 \\
\hline$\stackrel{\pi}{0}$ & 7640 & 3190 & 24,4 & 338 & 364 & 15 & 6504 & 267 \\
\hline 9 & 5100 & 4560 & 23,3 & 322 & 108 & 5 & 7704 & 331 \\
\hline 10 & 4080 & 6633 & 27,1 & 375 & 425 & 16 & 10903 & 403 \\
\hline \multicolumn{9}{|l|}{ Bragança } \\
\hline Média & 8116 & 3482 & 27,4 & 379 & 683 & 30 & 14635 & 633 \\
\hline D.p. & 841 & 1875 & 12,5 & 173 & 271 & 19 & 4945 & 303 \\
\hline \multicolumn{9}{|l|}{ Morais } \\
\hline Média & 6308 & 4608 & 27,7 & 383 & 439 & 16 & 11303 & 399 \\
\hline D.p. & 1943 & 1252 & 6,0 & 83 & 231 & 8 & 4746 & 102 \\
\hline \multicolumn{9}{|l|}{ Total } \\
\hline Média & 7212 & 4045 & 27,5 & 381,0 & 561 & 23 & 12969 & 516 \\
\hline D.p. & 1703 & 1616 & 9,2 & 128,0 & 270 & 16 & 4895 & 246 \\
\hline
\end{tabular}

\section{$4-$ Conclusóes}

Este estudo preliminar sobre o potencial da fitomineração nos solos serpentiníticos dos maciços de Bragança e Morais, permite concluir que:

- $\quad$ O teor de Ni total no solo e o biodisponível são bastante variáveis em ambos os maciços sendo maior no maciço de Bragança do que no de Morais, contrariamente ao que acontece com o $\mathrm{Cr}$, demonstrando uma diferente composição mineralógica e litológica dos dois maciços.

- Náo se observa uma relação de proporcionalidade direta entre as concentraçóes dos elementos biodisponíveis e totais, com exceção do $\mathrm{Cu}$, o que mostra uma diferente maturação dos solos e composição das rochas adjacentes.

- A hiperacumulação de Ni na planta não é dependente nem da concentração de Ni total no solo nem da fracção biodisponível, existindo outros factores que interferem no potencial de hiperacumulação desta espécie, como podem ser a relação $\mathrm{Ca} / \mathrm{Mg}$ no solo, a disponibilidade de nutrientes, o "stress" hídrico ou a competição entre oligoelementos. 
- A concentração de Ni nas partes aéreas é superiores à das raízes, pelo que em fitomineração apenas deverão ser utilizadas as partes aéreas. Além disso, e sendo esta espécie perene, poderá possibilitar cortes sucessivos, sem necessidade de sementeira, podendo aumentar em muito o seu potencial de extração em função do tempo.

- Nestas condiçóes naturais a concentraçáo máxima encontrada na planta, expressa em material seco é de cerca de $0.66 \% \mathrm{Ni}$ e a mínima de $0.15 \%$ de $\mathrm{Ni}$ tendo como média $0.41 \% \mathrm{Ni}$ ( $0.35 \%$ no maciço de Bragança e $0.46 \%$ no maciço de Morais).

- A biomassa média calculada foi de $7.2 \mathrm{t} / \mathrm{ha}$, com um mínimo de $4.1 \mathrm{t} / \mathrm{ha}$ e um máximo de $9.4 \mathrm{t} / \mathrm{ha}$, verificando-se maior produtividade no maciço de Bragança.

- A depleção do elemento no solo não é significativa, mesmo com o estabelecimento de culturas e com a utilização de agentes que promovam a biodisponibilidade de níquel no solo, não incluindo a atividade dos processos pedogénicos na formação de novo solo.

- $\quad$ O quantidade de Ni retirada pela planta apresenta uma média de cerca de 27.5 $\mathrm{kg} / \mathrm{ha}$, sendo similar em ambos os maciços, tendo um valor de cerca de $380 €$, considerando as cotaçóes de aneiro de 2012.

Os resultados preliminares obtidos permitem pensar na utilização de alguns destes espaços como potenciais produtores de Ni utilizando esta espécie endémica. Para tal haverá necessidade de conhecer melhor os mecanismos que levam à acumulação de $\mathrm{Ni}$ pelo Alyssum serpyllifolium subsp. lusitanicum, para se poder definir modos de cultivo desta espécie, levando à sua otimização, como a fertilização, a adição de agentes quelatantes, a hibridação ou a clonagem de exemplares, por forma a aumentar o seu potencial de hiperacumulação e produção de biomassa.

Agradecimentos - Este trabalho foi financiado pela FCT (Projecto PTDC/CTE-GEX/66710/2006).

\section{Referências Bibliográficas}

ADRIANO, D.C. (2001) - Trace elements in terrestrial environments: Biogeochemistry, bioavailability, and risks of metals, second ed. Springer-Verlag, Inc., New York. p. 866.

ARIANOUTSOU, M., RUNDEL, P.W. \& BERRY, W.L. (1993) - Serpentine endemics as biological indicators of soil elemental concentrations. In: Markert, (Ed.), Plants as Biomonitors. Indicators for Heavy Metals in the Terrestrial Environment. VCH-Publisher, Weinheim, pp. 179-189.

BAKER, A.J.M., PROCTOR, J. \& REEVES, R.D. (Eds.), (1993) - The Vegetation of Ultramafic (Serpentine) Soils. Intercept Ltd., Andover, UK, 509pp.

BROOKS, R.R. (1983) - Biological Methods of Prospecting for Minerals, John Willey, New York, 322pp.

BROOKS, R.R. (1987) - Serpentine and its Vegetation: A Multidisciplinary Approach. Discorides Press, Portland, Oregon. 454 pp.

BROOKS, R.R., SHAW, S. \& MARFIL, A.A. (1981) - Some observations on the ecology, metal uptake and nickel tolerance of Alyssum serpyllifolium subspecies fronm the Iberian península, Plant Ecology, V. 45, 3, 183-188pp

FAVAS, P., PRATAS, J. \& CONDE, L. (2003) - Acumulação de metais pesados e arsénio em solos e plantas das escombreiras e da envolvente das Minas de Vale das Gatas (Sabrosa - Vila Real - Portugal). VI Congresso 
Nacional de Geologia, in: Ciências da Terra, Volume V, 96-97, Departamento de Ciências da Terra da Faculdade de Ciências e Tecnologia da Universidade Nova de Lisboa. CD-Rom H49:H52.

FREITAS. H., PRATAS, M.N.V. \& PRATAS, J. (2004) - Analysis of serpentinophytes from north-east of Portugal for trace metal accumulation - relevance to the management of mine environment, Chemosphere, 54, 11, 1625-42.

PEREIRA E., RIBEIRO, A. \& SILVA, N. (1998) - Carta geológica de Portugal na escala 1:50000, folha 7-D Macedo de Cavaleiros. Serviços Geológicos de Portugal

GOOGLE EARTH. Acedido a 1/12/2011

KRUCKEBERG, A.R. (1984) - California serpentines: flora, vegetation, geology, soils and management problems. University of California Press, Berkeley, CA.

MENEZES DE SEQUEIRA, E. (1968) - Toxicity and movement of heavy metals in serpentinic soils (north-eastern Portugal), Agronomia Lusitana, 30, 2, 115-154.

MENEZES DE SEQUEIRA, E. \& PINTO DA SILVA, A.R. (1991) - The ecology of serpentinized areas of north-east Portugal, in: Roberts, B.A., Proctor, J. (Eds.), The Ecology of Areas with Serpentinized Rocks. A World Review. Kluwer Academic Publishers, Dordrecht, pp. 169-197.

NEIVA, J.M.C. (1948) - Rochas e minérios da regiáo Bragança-Vinhais. PhD Thesis. Universidade de Coimbra.

PINTO DA SILVA, A. R. (1968) - A flora e a vegetaçáo das áreas ultrabásicas do Nordeste Transmontano, Agronomia Lusitana, 30, 3-4, 175-364.

PRASAD, M.N.V., FREITAS, H. \& PRATAS, J. (2006) - Trace elements in plants and soils of abandoned mines from Portugal: significance for phytomanagement and biogeochemical prospecting, in: Prasad, M.N.V., Sajwan, K.S. and Ravi Naidu (Eds.), 2005, Trace Elements in the Environment: Biogeochemistry, Biotechnology and Bioremediation, CRC Press, USA., 507-521.

PRATAS, J.A.M.S. (1996) - Aplicações de Prospecção Biogeoquímica - selecção de espécies bioindicadoras em algumas áreas mineiras de Portugal, 3 volumes, PhD Thesis, Universidade de Coimbra, 1064.

REEVES, R.D., BAKER, A.J.M., BORHIDI, A. \& BERAZAIN, R. (1996) - Nickel-accumulating plants from the ancient serpentine soils of Cuba. New Phytologist 133, 217-224.

ROSS, S.M. (Ed.), (1994) - Toxic Metals in Soil and Plant Systems. Wiley, Chichester, UK. 